\title{
Limited effect of lymph node status on the metastatic pattern in colorectal cancer
}

\author{
Nikki Knijn ${ }^{1}$, Felice N. van Erning ${ }^{2,3}$, Lucy I.H. Overbeek ${ }^{4}$, Cornelis J.A. Punt ${ }^{5}$, \\ Valery E.P.P. Lemmens ${ }^{2,3}$, Niek Hugen ${ }^{6}$ and Iris D. Nagtegaal ${ }^{1}$ \\ ${ }^{1}$ Department of Pathology, Radboud University Medical Center, Nijmegen, The Netherlands \\ ${ }^{2}$ Netherlands Comprehensive Cancer Organisation, Eindhoven, The Netherlands \\ ${ }^{3}$ Department of Public Health, Erasmus MC University Medical Centre, Rotterdam, The Netherlands \\ ${ }^{4}$ PALGA Foundation, Houten, The Netherlands \\ ${ }^{5}$ Department of Medical Oncology, Academic Medical Center, University of Amsterdam, Amsterdam, The Netherlands \\ ${ }^{6}$ Department of Surgery, Radboud University Medical Centerl, Nijmegen, The Netherlands \\ Correspondence to: Iris D. Nagtegaal, email: Iris.Nagtegaal@radboudumc.nl \\ Keywords: colorectal neoplasms, neoplasm metastasis, lymph nodes, blood vessels, autopsy, Pathology Section \\ Received: February 09, $2016 \quad$ Accepted: April 05, 2016 \\ Published: April 27, 2016
}

\section{ABSTRACT}

Regional lymph node metastases in colorectal cancer (CRC) decrease outcome. Whether nodal metastases function as a biomarker, i.e. as a sign of advanced disease, or are in fact involved in the metastatic process is unclear. We evaluated metastatic patterns of CRC according to the lymph node status of the primary tumor.

A retrospective review of 1393 patients with metastatic CRC who underwent autopsy in the Netherlands was performed. Metastatic patterns of regional lymph node positive and negative CRC were compared and validated by population-based data from the Eindhoven Cancer Registry (ECR).

Patients with regional lymph node positive CRC more often developed peritoneal metastases ( $28 \%$ vs. $21 \%, p=0.003)$ and distant lymph node metastases $(25 \%$ vs. $15 \%, p<0.001)$. Incidences of liver and lung metastases were comparable. Data from the ECR confirmed our findings regarding peritoneal $(22.4 \%$ vs. $17.0 \%, p=0.003)$ and distant lymph node metastases $(15.8 \%$ vs. 9.7\%, $p<0.001)$.

Regional lymph node positive CRC show a slightly different dissemination pattern, with higher rates of peritoneal and distant lymph nodes metastases. Comparable incidences of liver and lung metastases support the hypothesis that dissemination to distant organs occurs independently of lymphatic spread.

\section{INTRODUCTION}

Despite intensive follow-up and increasing therapeutic options for colorectal cancer (CRC), metastatic disease remains the leading factor in CRC mortality. CRC most frequently metastasizes to the liver, lung and peritoneum, but other metastatic sites such as bone, spleen, brain and distant lymph nodes have been described.[1-3]

According to the mechanistical view of metastatic spread, tumor cells can disseminate to distant organs through two pathways: the vascular and the lymphatic pathway. The vascular hypothesis suggest that blood vessels transport tumor cells directly to distant organs. In the lymphatic pathway tumor cells may disseminate from regional lymph nodes to distant lymph nodes, reach the systemic circulation and subsequently form organ metastases.[4] The distinction between these pathways and their role in dissemination remains matter of debate.

Post-mortem studies offer a possibility to register both the extent and location of metastatic disease. Findings during autopsy may be considered the ultimate endpoint of disease. Autopsy studies are therefore usefull 
Table 1: Distribution of tumor and patient characteristics according to regional lymph node status of the primary tumor in the autopsy cohort

\begin{tabular}{|l|l|l|l|l|l|}
\hline Features & \multicolumn{2}{ll}{ N +} & \multicolumn{2}{l|}{ N- } & $P$-value \\
\hline & 879 & $(\%)$ & 514 & $(\%)$ & \\
\hline Gender & & & & & 0.375 \\
\hline Male & 514 & 58.5 & 313 & 60.9 & \\
\hline Female & 365 & 41.5 & 201 & 39.1 & \\
\hline Age at diagnosis & & & & & 0.681 \\
\hline$<60$ & 188 & 21.4 & 96 & 18.7 & \\
\hline $60-74$ & 408 & 46.4 & 247 & 48.1 & \\
\hline$\geq 75$ & 283 & 32.2 & 171 & 33.3 & \\
\hline Location of primary & & & & & 0.032 \\
\hline Proximal colon & 337 & 38.3 & 162 & 31.5 & \\
\hline Distal colon & 271 & 30.8 & 162 & 31.5 & \\
\hline Rectum & 203 & 23.1 & 135 & 26.3 & \\
\hline Colon, not specified & 68 & 7.7 & 55 & 10.7 & \\
\hline T Stage & & & & & $<0.001$ \\
\hline T1 & 0 & 0 & 7 & 1.4 & \\
\hline T2 & 37 & 4.2 & 53 & 10.3 & \\
\hline T3 & 605 & 68.8 & 338 & 65.8 & \\
\hline T4 & 193 & 22.0 & 101 & 19.6 & \\
\hline Not specified & 43 & 4.9 & 15 & 2.9 & \\
\hline Histology & & & & & 0.002 \\
\hline $\begin{array}{l}\text { Non-mucinous } \\
\text { adenocarcinoma }\end{array}$ & 695 & 79.1 & 441 & 85.8 & \\
\hline Mucinous adenocarcinoma & 156 & 17.7 & 68 & 13.2 & \\
\hline Signet ring cell & 28 & 3.2 & 5 & 1.0 & \\
\hline Onset of metastases & & & & & $<0.001$ \\
\hline Synchronous & 538 & 61.2 & 186 & 36.2 & \\
\hline Metachronous & 382 & 43.5 & 292 & 56.8 & \\
\hline $\begin{array}{l}\text { Number } \\
\text { metastases }\end{array}$ & 497 & 56.5 & 222 & 43.2 & \\
\hline 1 & & & & & \\
\hline$>1$ & 38.8 & 328 & 63.8 & \\
\hline & & & & $<0.001$ \\
\hline
\end{tabular}

$\mathrm{N}+$ : primary tumor with regional lymph node metastases;

$\mathrm{N}-$ : primary tumor without regional lymph node metastases.

for getting insight in the relevance of lymphatic spread in the dissemination of cancer. Most autopsy studies, have focused on metastatic patterns in one or more types of cancer, but have failed to address differentiating aspects such as lymph node involvement. A large autopsy study by Budczies et al. across major cancer types, showed higher rates of metastases in distant lymph nodes, peritoneal cavity, pleura, pericardial and adrenal glands in lymph node positive tumors.[5] Although this study has given insight into metastatic patterns, this was done by grouping various cancers together.

To gain insight in the relevance of lymphatic spread in the dissemination of $\mathrm{CRC}$, we evaluated patterns of metastases according to the lymph node status of the primary tumor in 1393 autopsies. To confirm the clinical relevance, we analyzed population-based data from the Eindhoven Cancer Registry.

\section{RESULTS}

In the autopsy cohort, there were 1393 patients with metastatic disease; 879 patients $(63 \%)$ with regional lymph node metastases $(\mathrm{N}+)$ and 514 patients $(37 \%)$ without regional lymph node involvement $(\mathrm{N}-)$. The distribution of patient and tumor characteristics according 
Table 2: Distribution of tumor and patient characteristics according to regional lymph node status of the primary tumor in the clinical cohort

\begin{tabular}{|c|c|c|c|c|c|}
\hline Features & $\mathbf{N +}$ & & N- & & $P$-value \\
\hline & 1711 & $(\%)$ & 671 & $(\%)$ & \\
\hline Gender & & & & & 0.583 \\
\hline Male & 952 & 55.6 & 365 & 54.4 & \\
\hline Female & 759 & 44.4 & 306 & 45.6 & \\
\hline Age at diagnosis & & & & & 0.008 \\
\hline$<60$ & 448 & 26.2 & 135 & 20.1 & \\
\hline $60-74$ & 814 & 47.6 & 342 & 51.0 & \\
\hline$\geq 75$ & 449 & 26.2 & 194 & 28.9 & \\
\hline Location of primary & & & & & 0.014 \\
\hline Proximal colon & 609 & 35.6 & 192 & 28.6 & \\
\hline Distal colon & 504 & 29.5 & 216 & 32.2 & \\
\hline Rectum & 572 & 33.4 & 252 & 37.6 & \\
\hline Colon, unknown & 26 & 1.5 & 11 & 1.6 & \\
\hline T Stage & & & & & $<0.001$ \\
\hline $\mathrm{T} 1$ & 7 & 0.4 & 12 & 1.8 & \\
\hline $\mathrm{T} 2$ & 83 & 4.8 & 89 & 13.3 & \\
\hline $\mathrm{T} 3$ & 1101 & 64.4 & 411 & 61.2 & \\
\hline $\mathrm{T} 4$ & 397 & 23.2 & 106 & 15.8 & \\
\hline Unknown & 123 & 7.2 & 53 & 7.9 & \\
\hline Histology & & & & & 0.230 \\
\hline $\begin{array}{l}\text { Non-mucinous } \\
\text { adenocarcinoma }\end{array}$ & 1562 & 91.3 & 621 & 92.5 & \\
\hline Mucinous adenocarcinoma & 121 & 7.1 & 45 & 6.7 & \\
\hline Signet ring cell & 28 & 1.6 & 5 & 0.8 & \\
\hline Onset of metastases & & & & & $<0.001$ \\
\hline Synchronous & 1155 & 67.5 & 318 & 47.4 & \\
\hline Metachronous & 556 & 32.5 & 353 & 52.6 & \\
\hline $\begin{array}{|lll|}\text { Number of distant } \\
\text { metastases }\end{array}$ & & & & & $<0.001$ \\
\hline 1 & 1067 & 62.4 & 460 & 68.6 & \\
\hline$>1$ & 644 & 37.6 & 211 & 31.4 & \\
\hline
\end{tabular}

$\mathrm{N}-$ : primary tumor without regional lymph node metastases;

$\mathrm{N}+$ : primary tumor with regional lymph node metastases

to regional lymph node status is presented in Table $1 . \mathrm{N}+$ patients more often had a higher T-stage (T3/T4: 90.8\% vs. $85.4 \%, \mathrm{p}<0.001)$, a tumor located in the proximal part of the colon $(38.3 \%$ vs. $31.5 \%, \mathrm{p}=0.01)$, mucinous or signet ring cell histology $(20.9 \%$ vs. $14.2 \%, \mathrm{p}=0.002)$, multiple metastases ( $56.5 \%$ vs. $43.2 \%, \mathrm{p}<0.001)$ and synchronous onset of metastases $(61.2 \%$ vs. $36.2 \%$, p $<0.001)$.

\section{Distribution of metastases}

The liver was the most frequent site of metastasis irrespective of regional lymph node status $(68 \%$ in $\mathrm{N}+$ and $67 \%$ in $\mathrm{N}-, \mathrm{p}=0.53$ ). Lung metastases occurred in $33 \%$ of $\mathrm{N}$ - patients and in $35 \%$ of $\mathrm{N}+$ patients $(\mathrm{p}=0.42$; Figure 1a, supplementary Figure 1a). There was a higher rate of peritoneal metastases in $\mathrm{N}+$ patients $(28 \% \mathrm{vs}$. $21 \%, \mathrm{p}=0.003$ ) and distant lymph node metastases were more often found in $\mathrm{N}+$ patients $(25 \%$ vs. $15 \%, \mathrm{p}<0.001)$. 
Table 3: Risk of developing distant metastases in the clinical cohort

\begin{tabular}{|c|c|c|c|c|}
\hline \multirow{2}{*}{$\begin{array}{l}\text { Clinicopathological } \\
\text { factors }\end{array}$} & $\begin{array}{l}\text { Risk of developing } \\
\text { liver metastases }\end{array}$ & $\begin{array}{l}\text { Risk of developing } \\
\text { lung metastases }\end{array}$ & $\begin{array}{l}\text { Risk of developing } \\
\text { peritoneal } \\
\text { carcinomatosis }\end{array}$ & $\begin{array}{l}\text { Risk of developing distant } \\
\text { lymph node metastases }\end{array}$ \\
\hline & $\begin{array}{l}\text { MV analyses } \\
\text { OR (95\% CI) } \\
\end{array}$ & $\begin{array}{l}\text { MV analyses } \\
\text { OR }(95 \% \text { CI })\end{array}$ & $\begin{array}{l}\text { MV analyses } \\
\text { OR (95\% CI) }\end{array}$ & $\begin{array}{l}\text { MV analyses } \\
\text { OR (95\% CI) }\end{array}$ \\
\hline $\begin{array}{l}\text { Age } \\
<59 \\
60-74 \\
\geq 75 \\
\end{array}$ & $\begin{array}{l}1.00 \\
0.99(0.78-1.25) \\
0.96(0.74-1.25) \\
\end{array}$ & $\begin{array}{l}1.00 \\
1.26(0.98-1.61) \\
1.13(0.85-1.50) \\
\end{array}$ & $\begin{array}{l}1.00 \\
0.85(0.65-1.11) \\
0.98(0.73-1.31) \\
\end{array}$ & $\begin{array}{l}1.00 \\
0.87(0.65-1.16) \\
\mathbf{0 . 6 7}(\mathbf{0 . 4 8 - 0 . 9 4 )})^{*}\end{array}$ \\
\hline $\begin{array}{l}\text { Gender } \\
\text { Male } \\
\text { Female }\end{array}$ & $\begin{array}{l}1.00 \\
\mathbf{0 . 6 0}(\mathbf{0 . 5 0 - 0 . 7 2}) * * *\end{array}$ & $\begin{array}{l}1.00 \\
1.02(0.83-1.24)\end{array}$ & $\begin{array}{l}1.00 \\
1.19(0.96-1.47)\end{array}$ & $\begin{array}{l}1.00 \\
1.15(0.90-1.46)\end{array}$ \\
\hline $\begin{array}{l}\text { Location of tumor } \\
\text { Proximal colon } \\
\text { Distal colon } \\
\text { Rectum } \\
\text { not specified } \\
\end{array}$ & $\begin{array}{l}1.00 \\
\mathbf{1 . 6 4}(\mathbf{1 . 3 0 - 2 . 0 8 )} * * * \\
\mathbf{1 . 3 3}(\mathbf{1 . 0 5}-\mathbf{1 . 6 7}) * \\
0.76(0.37-1.54)\end{array}$ & $\begin{array}{l}1.00 \\
1.39(\mathbf{1 . 0 6}-1.81) * \\
\mathbf{2 . 2 5}(\mathbf{1 . 7 4 - 2 . 8 9 )} * * * * \\
1.43(0.63-3.23)\end{array}$ & $\begin{array}{l}1.00 \\
\mathbf{0 . 6 0}(\mathbf{0 . 4 7 - 0 . 7 6 )} * * * \\
\mathbf{0 . 2 4}(\mathbf{0 . 1 8 - 0 . 3 2 )} * * * \\
1.20(0.59-2.46) \\
\end{array}$ & $\begin{array}{l}1.00 \\
0.88(0.65-1.20) \\
0.78(0.58-1.06) \\
0.88(0.35-2.23)\end{array}$ \\
\hline $\begin{array}{l}\text { T-stage } \\
\text { T1-2 } \\
\text { T3 } \\
\text { T4 } \\
\text { not specified } \\
\end{array}$ & $\begin{array}{l}1.23(0.86-1.76) \\
1.00 \\
\mathbf{0 . 4 8}(\mathbf{0 . 3 8 - 0 . 6 1 )} * * * \\
1.14(0.74-1.75) \\
\end{array}$ & $\begin{array}{l}1.00(0.71-1.42) \\
1.00 \\
1.10(0.84-1.43) \\
1.32(0.87-2.01) \\
\end{array}$ & $\begin{array}{l}\mathbf{0 . 4 2}(\mathbf{0 . 2 3}-\mathbf{0 . 7 7}) * * \\
1.00 \\
\mathbf{2 . 1 8}(\mathbf{1 . 7 2}-2.77) * * * \\
1.26(0.82-1.95) \\
\end{array}$ & $\begin{array}{l}1.17(0.75-1.84) \\
1.00 \\
1.28(0.94-1.74) \\
\mathbf{3 . 7 6}(\mathbf{2 . 3 8}-\mathbf{5 . 9 5}) * * * \\
\end{array}$ \\
\hline $\begin{array}{l}\text { N-stage } \\
\text { N0 } \\
\text { N1 } \\
\text { N2 } \\
\end{array}$ & $\begin{array}{l}1.00 \\
1.13(0.90-1.41) \\
1.23(0.95-1.58) \\
\end{array}$ & $\begin{array}{l}1.00 \\
1.25(0.99-1.59) \\
0.92(0.70-1.22)\end{array}$ & $\begin{array}{l}1.00 \\
1.14(0.87-1.49) \\
\mathbf{1 . 4 0}(\mathbf{1 . 0 5}-\mathbf{1 . 8 7}) * \\
\end{array}$ & $\begin{array}{l}1.00 \\
1.97(1.43-2.72) * * * \\
3.03(2.14-4.29) * * *\end{array}$ \\
\hline $\begin{array}{l}\text { Histology } \\
\text { Non-mucinous } \\
\text { adenoca } \\
\text { Mucinous adenoca }\end{array}$ & $\begin{array}{l}1.00 \\
0.46(0.34-0.62) * * *\end{array}$ & $\begin{array}{l}1.00 \\
0.74(0.52-1.05)\end{array}$ & $\begin{array}{l}1.00 \\
2.53(1.84-3.47) * * *\end{array}$ & $\begin{array}{l}1.00 \\
1.20(0.82-1.77)\end{array}$ \\
\hline $\begin{array}{l}\text { Onset of metastases } \\
\text { Synchronous } \\
\text { Metachronous }\end{array}$ & $\begin{array}{l}1.00 \\
0.38(0.31-0.47)^{* * * *}\end{array}$ & $\begin{array}{l}1.00 \\
4.10(3.31-5.09) * * *\end{array}$ & $\begin{array}{l}1.00 \\
1.09(0.86-1.37)\end{array}$ & $\begin{array}{l}1.00 \\
4.35(3.31-5.71) * * *\end{array}$ \\
\hline
\end{tabular}

In multivariate analyses adjustments were made for age, gender, location of the primary tumor, primary tumor stage, primary lymph node stage, tumor histology and onset of metastases. ${ }^{*} p<0.05, * * p<0.01, * * * p<0.001$. Abbreviations: MV: multivariate; OR: Odds Ratio; adenoca: adenocarcinoma.

Other significant differences were found for metastases in omentum, spleen and pancreas (N+ vs. N-; 9.2 vs. $3.3 \%$, $\mathrm{p}<0.001,2.8$ vs. $1.0 \%, \mathrm{p}=0.02$, and 2.6 vs. $1.0 \%, \mathrm{p}=0.04$, respectively).

When patients were subdivided according to the location of the primary tumor, a higher percentage of lung metastases in $\mathrm{N}+$ rectal cancer as compared to $\mathrm{N}+$ colon cancer $(43.8 \%$ vs. $32.1 \%, p=0.001)$ and higher percentage of peritoneal metastases in $\mathrm{N}+$ colon cancer as compared to $\mathrm{N}+$ rectal cancer $(30.8 \%$ vs. $19.2 \%, \mathrm{p}=0.002)$ was found. This could be related to the higher overall percentage of lung metastases in rectal cancer compared with colon cancer $(42.6 \%$ vs. $31.3 \%, \mathrm{p}<0.001)$ and of peritoneal metastases in colon cancer compared with rectal cancer $(28.1 \%$ vs. $17.2 \%, \mathrm{p}<0.001)$. $\mathrm{N}+$ colon cancers more often had peritoneal metastases and distant lymph node metastases compared with $\mathrm{N}$ - colon cancers $(24.0 \%$ vs. $14.0 \%, p<0.001$, and $30.8 \%$ vs. $23.2 \%, p=0.009$, respectively). In rectal cancer only distant lymph node metastases were more often seen in $\mathrm{N}+$ than in $\mathrm{N}$ - patients (28.1\% vs. $18.5 \%, \mathrm{p}=0.05)$.

\section{Validation of findings}

A total of 2382 patients with metastatic colorectal cancer from the Eindhoven Cancer Registry (ECR) was included, of which 1711 patients (71.8\%) had regional lymph node metastases and 671 patients $(28.2 \%)$ did not. Median follow-up was 5.0 years (range $1.2-8.8$ years). The distribution of patient and tumor characteristics according to lymph node status is presented in Table 2.

$\mathrm{N}+$ patients more often developed peritoneal metastases and distant lymph node metastases $(22.4 \%$ vs. $17.0 \%, \mathrm{p}=0.003$, and $15.8 \%$ vs. $9.7 \%, \mathrm{p}<0.001)$. Moreover, there was a higher percentage of liver metastases and a lower percentage of lung metastases in $\mathrm{N}+$ patients compared with $\mathrm{N}$ - patients $(71.6 \%$ vs. $66.3 \%, \mathrm{p}=0.01$ and 


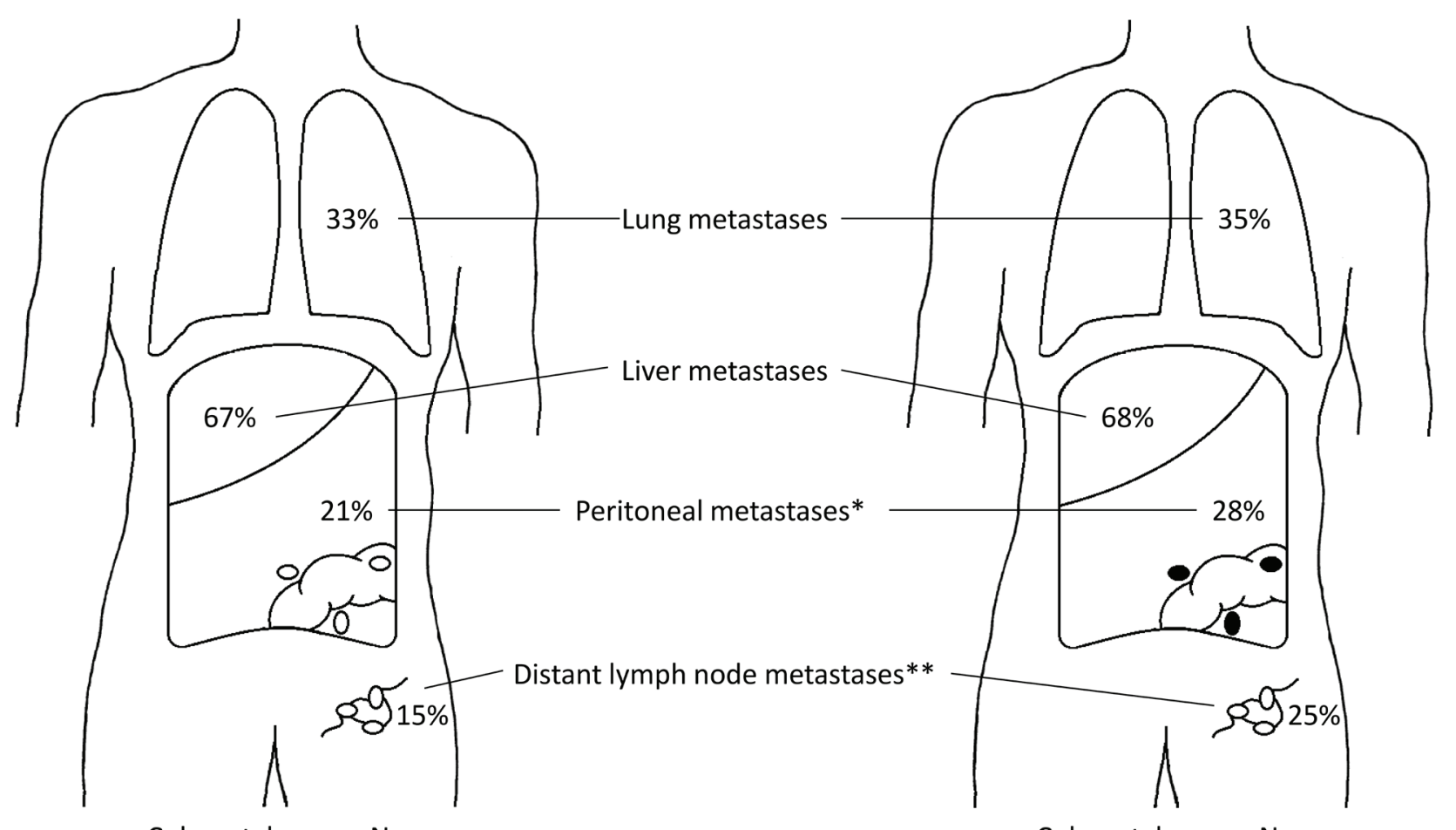

Colorectal cancer $\mathrm{N}$ -

Colorectal cancer $\mathrm{N}+$

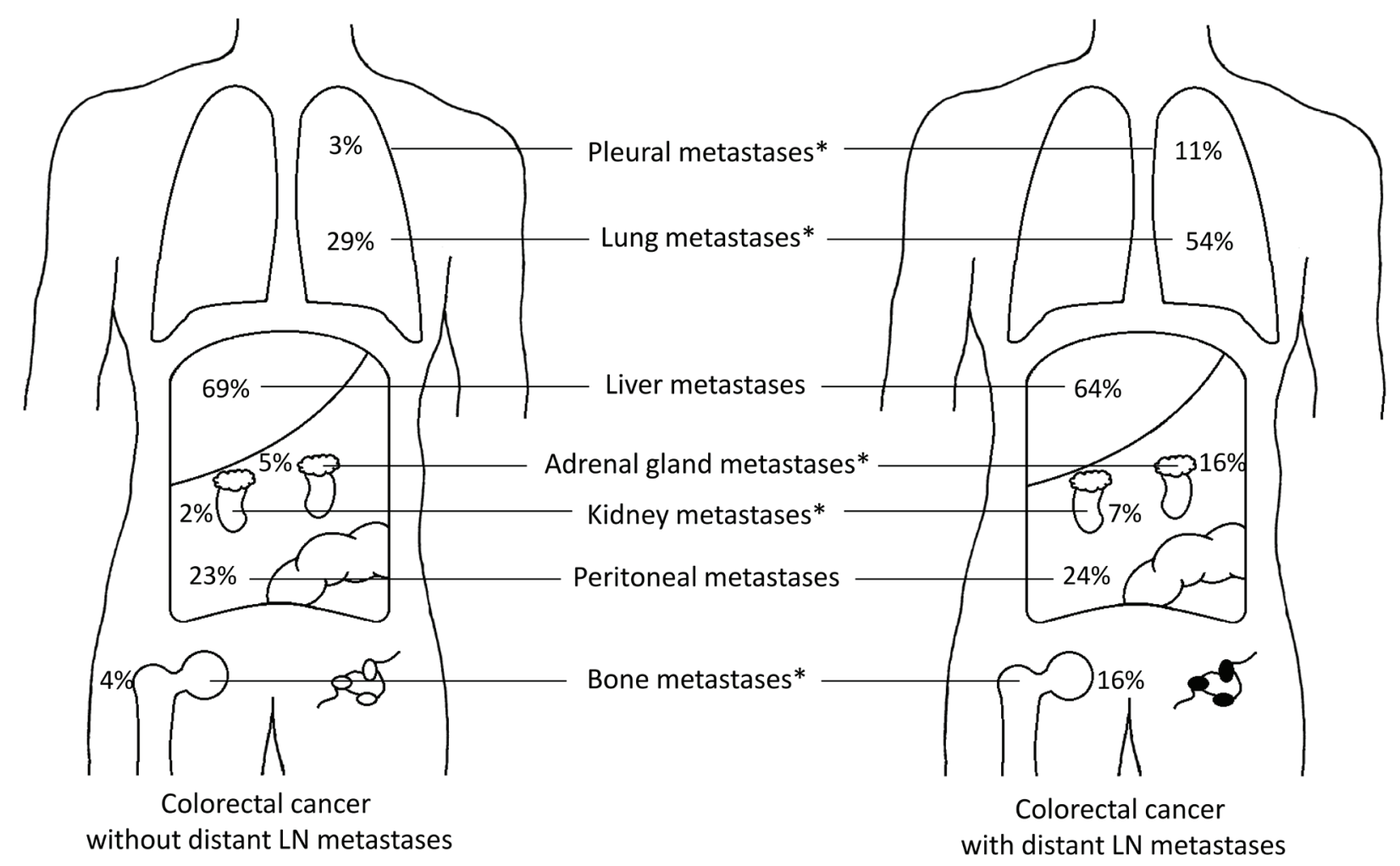

Figure 1: a. Distribution of CRC metastases according to regional lymph node status in the autopsy cohort. Left figure shows the distribution of metastases for regional lymph node negative primary tumors, right figure shows the distribution of metastases for regional lymph node positive primary tumors. ${ }^{*} p=0.003,{ }^{* *} p<0.001$. b. Distribution of CRC metastases according to distant lymph node positivity in the autopsy cohort. Left figure shows the distribution of metastases for primary tumors without distant lymph node metastases, right figure shows the distribution of metastases for primary tumors with distant lymph node metastases. $* p<0.001$. 
$23.7 \%$ vs. $27.7 \%, \mathrm{p}=0.04$, respectively).

Logistic regression analyses identified several clinicopathological factors that were associated with location specific metastases (Table 3). Rectal tumors were associated with a higher risk of developing liver and lung metastases (OR for liver: 1.33 (1.05-1.67), $\mathrm{p}<0.05$, OR for lung: 2.25 (1.74-2.89), $\mathrm{p}<0.001)$, and with a lower risk of developing peritoneal carcinomatosis (OR: $0.24(0.18-0.32), \mathrm{p}<0.001)$. T4 tumors less often led to liver metastases (OR: $0.48(0.38-0.61), p<0.001)$ and were associated with a higher risk of developing peritoneal carcinomatosis (OR: 2.18 (1.72-2.77), $\mathrm{p}<0.001)$. Lymph node positive tumors were associated with an increased risk of developing distant lymph node metastases, especially N2 tumors (OR: 3.03 (2.14-4.29), $\mathrm{p}<0.001)$. N2 tumors were also associated with peritoneal carcinomatosis (OR: $1.40(1.05-1.87), \mathrm{p}<0.05)$. Mucinous tumors less often led to liver metastases (OR: 0.46 (0.34$0.62), p<0.001)$ and were associated with a higher risk of developing peritoneal carcinomatosis (OR: 2.53 (1.843.47), $\mathrm{p}<0.001)$.

\section{Distant lymph node metastases}

To provide further insight into the relevance of regional lymph node metastases for distant lymph node metastases, data was analyzed from 1024 cases with at least ten lymph nodes retrieved with the primary tumor. We found an increasing rate of distant lymph node metastases according to the number of positive lymph nodes detected in the primary tumor (Figure 2). Data from the ECR showed an increase from $9.1 \%$ in patients without positive lymph nodes to $27.1 \%$ in patients with more than twelve positive lymph nodes detected in the primary tumor $(p<0.001)$. Data from the autopsy study showed an increase from $8.2 \%$ to $48.4 \%(\mathrm{p}<0.001)$.
Compared with patients without distant lymph node metastases, patients with distant lymph node metastases more often had metastases in lung ( $57 \%$ vs. $29 \%$, $\mathrm{p}<0.001)$, pleura $(11 \%$ vs. $3 \%, \mathrm{p}<0.001)$, bone $(16 \%$ vs. $4 \%, \mathrm{p}<0.001)$, adrenal gland ( $16 \%$ vs. $5 \%, \mathrm{p}<0.001)$ and kidney ( $7 \%$ vs. $2 \%, \mathrm{p}<0.001$ ) (Figure $1 \mathrm{~b}$, Supplementary Figure 1b).

\section{DISCUSSION}

This is the first large study comparing metastatic patterns according to lymph node status of CRC. The most common site of distant metastasis was liver followed by lung, peritoneum and distant lymph nodes, with percentages comparable to literature.[2, 6] Peritoneal and distant lymph node metastases occurred more often in regional lymph node positive CRC, while liver and lung metastases occurred in a similar percentage. Our multivariate analysis shows that next to established risk factors for peritoneal carcinomatosis, like T-stage, proximal location and mucinous carcinoma, regional lymph node metastases are an important risk factor. This is in line with other studies[7-10] making it likely that lymph node metastases are involved in the etiology of peritoneal carcinomatosis. The omentum is a preferential site of peritoneal metastases and the lymphoid milky spots in the omentum are a homing site for metastatic cancer cells.[11] Tumor cells in the omentum can reach the peritoneal cavity by direct growth. The milky spots and the anti-inflammatory function of the omentum suggest a relation between the peritoneum and the lymphatic system. Moreover, chylous ascites can occur after obstruction or resection of extra-peritoneal located lymphatic vessels, providing more evidence for direct communications between lymphatic vessels and the peritoneal cavity.[12] The finding that regional lymph node positive CRC spread

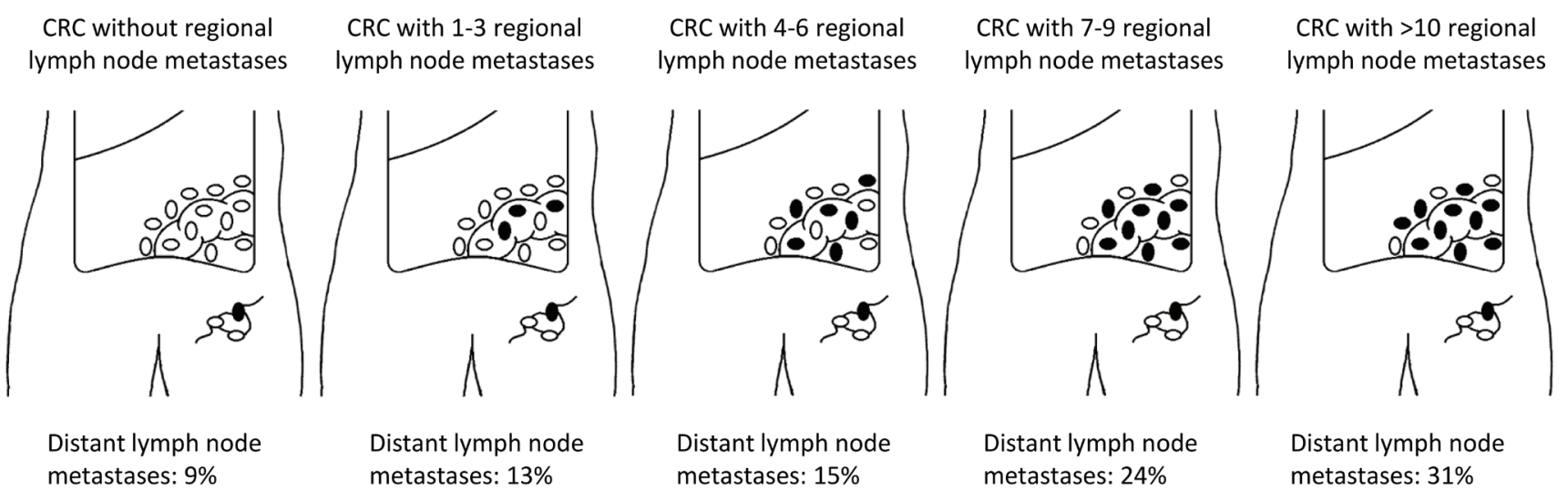

Figure 2: Percentage of patients with distant lymph node metastases according to the number of positive lymph nodes in primary tumor. Selection of patients with more than ten lymph nodes examined $(N=1024$ pts; autopsy cohort $=258$ pts; clinical cohort $=766 \mathrm{pts}), p<0.001$. 
more often to distant lymph nodes is in line with others[5] and in support of the first part of the lymphatic hypothesis. However, since no difference was observed in liver metastases, the vascular hypothesis seems more important for liver metastases.[4] Based on the lymphatic hypothesis we expected that lymphatic drainage of the thoracic duct into the venous system would lead to a higher incidence of lung metastases in regional lymph node positive CRC. However, we found comparable incidences of lung metastases in the whole group of patients with regional lymph node positive CRC $(n=1590)$. In a subgroup of patients with distant lymph node metastases analysed in the autopsy cohort $(\mathrm{n}=297)$, we did find increased lung and pleural metastases, suggesting that for this small subgroup the lymphatic pathway is important for the metastatic pattern. Our unique setup, where we validated findings from autopsy studies in a registry based cohort with prospectively collected data, illustrated only a limited influence of lymph node metastases on metastatic patterns in CRC. Autopsy studies contain selected populations, in which patients are included who have died postoperatively, had an unexpected clinical course, or died of other causes than CRC. Nevertheless, autopsy studies offer a unique opportunity to study the final distribution of metastases. During autopsy all intra-abdominal and intra-thoracic organs are extensively explored, revealing more metastases than would have been detected with imaging. This explains the high rate of distant lymph node metastases found in the autopsy cohort compared to the clinical cohort. $17 \%$ of cases $(286 / 1679)$ in the autopsy cohort and $22 \%$ of cases (673/3092) in our clinical cohort had to be excluded because of non-documentation of the regional lymph node status, since there was no resection of the primary tumor. This might have caused bias in our patient selection. Moreover, there could have been variations in the quality of the autopsy examination and in the pathological examination of resected primary tumor specimens, which will have occurred in both groups. Therefore we do not expect a significant bias. We cannot exclude the possibility that changes in the management of colorectal cancer between 1991-2010, would have had an influence on the metastatic patterns established at autopsy. The introduction of radiotherapy, chemotherapy, targeted therapy and surgery of metastatic lesions, might have shifted the presence of metastases to more uncommon sites. However, our main findings were validated in the population study with a narrower time frame. This study shows that regional lymph node involvement in CRC is associated with a higher rate of peritoneal metastases and distant lymph node metastases. Our findings support the hypothesis that metastases to the liver and lung occur independently of lymphatic spread. Regional lymph node metastases function as a biomarker, i.e. as a sign of advanced disease, and seem only mechanisticly involved in the process of metastases in a small subgroup of patients with spread via the distant lymph nodes. Unfortunately, the presence of vascular invasion is grossly underreported in pathology reports, making a separate analysis for vascular invasion not possible. Therefore, our findings can only indirectly support the vascular pathway as a mechanism for development of common distant metastases, such as liver and lung metastases. However, the current recognition of extramural vascular invasion in the staging and treatment of colorectal cancer[13-15] seems justified.

\section{MATERIALS AND METHODS}

\section{Study design}

An autopsy cohort was selected to compare patterns of metastases according to the regional lymph node status of the primary tumor. Findings at autopsy are the ultimate endpoint of disease, making autopsy reports suitable for analyzing the extend of disease. Autopsy data are derived from a restricted patient population, therefore a prospectively collected cohort of the Eindhoven Cancer Registry (ECR) was chosen for validation. First, differences in metastatic pattern according to the lymph node status of the primary tumor were analysed. Due to the close relationship between lymphatic spread, regional and distant lymph node metastases, separate analyses were performed in tumors with and without distant lymph node metastases in the autopsy cohort.

\section{Autopsy cohort}

A total of 1679 patients with metastatic colorectal cancer was identified in an autopsy study by Hugen et al.[16] Data from this study was used for the present analyses. Patients were selected from a retrospective review of pathological and autopsy records from the nationwide network and registry of histo- and cytopathology in the Netherlands (PathologischAnatomisch Landelijk Geautomatiseerd Archief; PALGA) [17] Patients who were diagnosed with metastatic CRC and autopsied between 1991 and 2010 were selected. In the Netherlands post-mortem examination is performed at the request of the family or treating doctor and is carried out by a pathologist. All autopsies included in this study were performed in order to obtain information on the medical status of the deceased or to determine the exact cause of death. No forensic autopsies were included. Tumor histology was assessed by different pathologists. Local staging of the primary tumor was reconstructed according to the TNM classification $\left(5^{\text {th }}\right.$ edition).[18] Allocation to the lymph node category was based on pathological examination of the original resection specimen or on the autopsy specimen. For regional lymph nodes metastasis only positive lymph 
nodes along the colon or rectum, plus the nodes along the major arteries that supply blood to the colon or rectum were considered. Metastasis in all other nodes were considered distant lymph nodes metastases. Patients of whom the primary N-stage could not be retrieved were excluded $(n=286)$. Colon tumors were classified as proximal if they were found in cecum, ascending colon or transverse colon, and classified as distal if they were found in the descending or sigmoid colon. Data on gender and age were available for all cases, but further clinical information (e.g. treatment or disease course) was lacking in this database and could not be retrieved. Metastatic disease was determined during pathological assessments of resected or biopsied specimens during follow-up or during autopsy. All metastases found at autopsy were histologically confirmed. Metastases that were detected more than six months after surgery of the primary tumor were considered metachronous.[19]

\section{Clinical cohort}

Data were retrieved from the Eindhoven Cancer Registry (ECR) which collects data of all patients with newly diagnosed cancer in the southeastern part of the Netherlands.[20] All patients who were diagnosed with CRC between 2003 and 2008 were included if they had synchronous metastases or developed metastases during follow-up untill 2010-2011 ( $\mathrm{n}=3092)$. End of follow-up was defined as the date of death or end of data collection in 2010-2011. Patients who underwent an autopsy were excluded to prevent overlap with the initial cohort $(n=37)$. Moreover, patients with missing N-stage $(n=673)$ were excluded. Tumor staging, classification of primary tumor location and onset of metastatic disease were performed as described for the autopsy cohort. Allocation to the lymph node category was based on pathological examination of the original resection specimen. Anatomical sites of metastases were registered according to the International Classification of Diseases for Oncology (ICD-O).[21] Patterns of metastatic disease were determined based on the first site of metastasis.

\section{Statistical analysis}

The $\chi^{2}$ test was used to compare baseline characteristics between regional lymph node positive and negative CRC. Logistic regression analysis was used to analyze patient and tumor characteristics associated with location specific metastases. This analysis was performed in the clinical cohort, because of potential bias in the autopsy cohort. Odds ratio's (ORs) were provided with their $95 \%$ confidence interval (CI). In multivariate (MV) analyses adjustments were made for age, gender, primary T-stage, primary $\mathrm{N}$-stage, differentiation grade of primary tumor, localization of primary tumor, primary tumor histology and onset of metastases. Statistical analyses were performed using SAS/STAT1 statistical software (SAS system 9.3, SAS Institute, Cary, North Carolina, USA) and the statistical software package SPSS 20.0 (SPSS Inc, Chicago, Illinois, USA). All tests of significance were two sided and differences at $\mathrm{P}$-values of $\leq 0.05$ were considered to be significant.

\section{GRAND SUPPORT}

N.Knijn is currently receiving a personal grant from the Dutch Cancer Society (KUN 2011-5251).

\section{CONFLICTS OF INTEREST}

All authors declare no conflicts of interest.

\section{REFERENCES}

1. Disibio G and French SW. Metastatic patterns of cancers: results from a large autopsy study. Archives of pathology \& laboratory medicine. 2008; 132:931-939.

2. Hess KR, Varadhachary GR, Taylor SH, Wei W, Raber $\mathrm{MN}$, Lenzi R and Abbruzzese JL. Metastatic patterns in adenocarcinoma. Cancer. 2006; 106:1624-1633.

3. Weiss L, Grundmann E, Torhorst J, Hartveit F, Moberg I, Eder M, Fenoglio-Preiser CM, Napier J, Horne CH, Lopez $\mathrm{MJ}$ and et al. Haematogenous metastatic patterns in colonic carcinoma: an analysis of 1541 necropsies. The Journal of pathology. 1986; 150:195-203.

4. Alitalo A and Detmar M. Interaction of tumor cells and lymphatic vessels in cancer progression. Oncogene. 2012; 31:4499-4508.

5. Budczies J, von Winterfeld M, Klauschen F, Bockmayr M, Lennerz JK, Denkert C, Wolf T, Warth A, Dietel M, Anagnostopoulos I, Weichert W, Wittschieber D and Stenzinger A. The landscape of metastatic progression patterns across major human cancers. Oncotarget. 2015; 6:570-583. doi: 10.8632/oncotarget. 2677.

6. Welch JP and Donaldson GA. The clinical correlation of an autopsy study of recurrent colorectal cancer. Annals of surgery. 1979; 189:496-502.

7. Jayne DG, Fook S, Loi C and Seow-Choen F. Peritoneal carcinomatosis from colorectal cancer. The British journal of surgery. 2002; 89:1545-1550.

8. Segelman J, Granath F, Holm T, Machado M, Mahteme $\mathrm{H}$ and Martling A. Incidence, prevalence and risk factors for peritoneal carcinomatosis from colorectal cancer. The British journal of surgery. 2012; 99:699-705.

9. van Gestel YR, Thomassen I, Lemmens VE, Pruijt JF, van Herk-Sukel MP, Rutten HJ, Creemers GJ and de Hingh IH. Metachronous peritoneal carcinomatosis after curative treatment of colorectal cancer. European journal of surgical oncology. 2014; 40:963-969. 
10. van Santvoort HC, Braam HJ, Spekreijse KR, Koning NR, de Bruin PC, de Vries Reilingh TS, Boerma D, Smits AB, Wiezer MJ and van Ramshorst B. Peritoneal carcinomatosis in 44 colorectal cancer: occurrence and risk factors. Annals of surgical oncology. 2014; 21:1686-1691.

11. Koppe MJ, Nagtegaal ID, de Wilt JH and Ceelen WP. Recent insights into the pathophysiology of omental metastases. Journal of surgical oncology. 2014; 110:670675.

12. Tulunay G, Ureyen I, Turan T, Karalok A, Kavak D, Ozgul N, Ocalan R, Tapisiz OL, Boran N and Kose MF. Chylous ascites: analysis of 24 patients. Gynecologic oncology. 2012; 127:191-197.

13. Betge J, Pollheimer MJ, Lindtner RA, Kornprat $\mathrm{P}$, Schlemmer A, Rehak P, Vieth M, Hoefler G and Langner C. Intramural and extramural vascular invasion in colorectal cancer: prognostic significance and quality of pathology reporting. Cancer. 2012; 118:628-638.

14. Chand M, Bhangu A, Wotherspoon A, Stamp GW, Swift RI, Chau I, Tekkis PP and Brown G. EMVI-positive stage II rectal cancer has similar clinical outcomes as stage III disease following pre-operative chemoradiotherapy. Annals of oncology. 2014; 25:858-863.

15. Petersen VC, Baxter KJ, Love SB and Shepherd NA. Identification of objective pathological prognostic determinants and models of prognosis in Dukes' B colon cancer. Gut. 2002; 51:65-69.

16. Hugen N, van de Velde CJ, de Wilt JH and Nagtegaal ID. Metastatic pattern in colorectal cancer is strongly influenced by histological subtype. Annals of oncology. 2014; 25:651657.
17. Casparie M, Tiebosch AT, Burger G, Blauwgeers H, van de Pol A, van Krieken JH and Meijer GA. Pathology databanking and biobanking in The Netherlands, a central role for PALGA, the nationwide histopathology and cytopathology data network and archive. Cellular oncology. 2007; 29:19-24.

18. Fleming ID CS, Henson DE, Hutter RVP, Kennedy BJ, Murphy GP, O'Sullivan B, Sobin LH, Yarbro JW, editors. (1997). American Joint Committe on Cancer (AJCC). AJCC Cancer Staging Manual. (Philadelphia: Lippincott JB).

19. Mekenkamp LJ, Koopman M, Teerenstra S, van Krieken JH, Mol L, Nagtegaal ID and Punt CJ. Clinicopathological features and outcome in advanced colorectal cancer patients with synchronous vs metachronous metastases. British journal of cancer. 2010; 103:159-164.

20. Coebergh JW, Verhagen-Teulings MT, Crommelin MA, Bakker D and van der Heijden L. [Trends in incidence of cancer in southeast North Brabant and North Limburg during 1975-1986; report from the IKZ/SOOZ cancer registration (Integrated Cancer Center South/Cooperative Organization Oncology Hospitals)]. Nederlands tijdschrift voor geneeskunde. 1990; 134:754-760.

21. Fritz AG PC, Jack A, Shanmugaratnam K, Sobin L, Parkin DM, Whelan S. (2000). International classification of diseases for oncology, 3rd edition. In: Fritz AG PC, Jack A, Shanmugaratnam K, Sobin L, Parkin DM, Whelan S., ed. (Geneva: World Health Organization). 